\title{
Saphanus piceus perovici n. ssp. from Pag Island, Croatia (Coleoptera Cerambycidae Spondylidinae Saphanini)
}

\author{
Pierpaolo Rapuzzi' \& Toni Koren² \\ 1Pierpaolo Rapuzzi, via Cialla 48, 33040 Prepotto, Udine, Italy; e-mail: info@ronchidicialla.it \\ ${ }^{2}$ Toni Koren, Association Hyla, Lipovec I n. 7, 10000 Zagreb, Croatia; e-mail: koren.toni1@gmail.com
}

\begin{abstract}
Saphanus piceus perovici n. ssp. (Coleoptera Cerambycidae Spondylidinae Saphanini) from Pag Island (Croatia) is here described. The new subspecies is related with the subspecies Saphanus piceus ganglbaueri Brancsik, 1886 described from Montenegro and known from the central and southern part of former Yugoslavia, Albania, Bulgaria, and Greece. The new subspecies is very interesting also due to the peculiar habitat where it was collected: very dry and warm.
\end{abstract}

KEY WORDS Coleoptera; Cerambycidae; Spondilidynae; Saphanus; new subspecies; Croatia.

Received 19.11.2019; accepted 16.12.2019; published online 30.12.2019

\section{INTRODUCTION}

While studying the Cerambycidae collected in various regions of Croatia we found a small series of Saphanus Serville, 1834 collected in Pag Island (northern Dalmatia) that, after a deeper study, appears to belong to a new taxon described in this paper. The genus Saphanus until now has been composed by two species: S. piceus (Laicharting, 1784) described from Austria (Weiherburg, Insbruck) and S. kadleci Rapuzzi et Sama, 2014 described from West Turkey (Sakarya) (Rapuzzi \& Sama, 2014). After a revision of the group (Sama \& Rapuzzi, 1993; Löbl \& Smetana, 2010), S. piceus was splitted in three subspecies: the nominal form from Central Europe, Italy, France and northern Balkan peninsula, S. piceus ganglbaueri Brancsik, 1886 described from Montenegro (Savina) and widespread in central and southern Balkan peninsula to central Greece and S. piceus bartolonii Sama et Rapuzzi, 1993 (Greece, Ossa mountain) known from the eastern mountains of continental Greece (Ossa range and Pilion range) only. The new sub- species is close, due to its characteristics, to $S$. piceus ganglbaueri. It is very interesting due to its biotope as well. It is the very first population of Saphanus that is known from the Adriatic islands. The habitat where it was collected is very dry and hot, completely different from any habitat where all the species of the tribe Saphanini normally live, except for Oxypleurus Mulsant, 1839 (Fig. 1).

\section{RESULTS}

\section{Systematics}

Ordo COLEOPTERA Linnaeus, 1758

Familia CERAMBYCIDAE Latreille, 1802

Subfamilia SPONDYLIDINAE Serville, 1832

Tribus SAPHANINI Gistel, 1848

Genus Saphanus Serville, 1834

Species piceus (Laicharting, 1784) Serville, 1832

Saphanus piceus perovici n. sp. (Figs. 2, 3)

Holotypus male. Croatia, Pag Island, Sveti 
Petar, north of Košljun, $44,427270^{\circ} \mathrm{N} 15,038829^{\circ} \mathrm{E}$, 11.VII.2015, collected at light, T. Koren legit (coll. T. Koren). Paratypes: 1 male and 1 female, same data as holotype (P. Rapuzzi collection and T. Koren collection).

DesCription OF the Holotype. Length 17.5 $\mathrm{mm}$, width $5.5 \mathrm{~mm}$. Color pitchy black, antennae slightly lighter. Head long, deep punctured, with a deep furrow in the middle of the front and between the eyes. The points are big and deep, sometimes fused together. Pubescence made by long erect brownish setae, more concentrated near the eyes and the antennal tubercles. Eyes big, deeply emarginate. Cheeks short. Antennal tubercles prominent, widely separate in the middle. Pronotum as long as wide, constricted toward the base. Lateral sides with a prominent and acute tooth positioned just up to the middle. Pronotum with very regular and deep punctures, with a shining and impunctate line in the middle. Pubescence on pronotum made by semierect hairs mainly concentrated close to the lateral sides. Scutellum longer that wide, rounded apically. Very thin punctures with short black recumbent setae. Elytra with parallel sides, rounded apically. The elytral punctation is regular, made by dense, medium-sized punctures with the same density all over the elytra except for the apical fifth where they are lighter and sparser. From each point starts a short, semi-recumbent, dark brown setae. On the disk there are the vestiges of three carina on each elytron that are quite covered by the regular punctation. Legs long and strong. Femora enlarged with a tooth on the inner side of the medium and hind legs. Tibiae arched, strongly in the middle and hind ones. Punctation made by dense points larger and stronger on the tibiae than the femora. The inner side of each tibia shows a sculpture made by many granules that gives a wrinkled appearance. Slender antennae, reaching last fifth of the elytral length. Third segment twice than the second and fourth little shorter than the scape. Segments from the fifth to the tenth with an apical tooth on the outside side, more evident and prominent from the seventh segment to the tenth. Maxillary palps very long, the apical segment axe-shaped.

VARIABILITY. The second known male (length $16.0 \mathrm{~mm}$., width $5.0 \mathrm{~mm}$.) is very similar to the type. The color of the legs is a little lighter and the vestiges of the elytral carina are less visible. The fe- male (Fig. 3), only one female specimen available (length $17.5 \mathrm{~mm}$., width $7.5 \mathrm{~mm}$.), shows the same dimorphism typical of the genus Saphanus. The length of antennae is shorter, exceeding the half of the elytral length only with the last segment. The elytral shape is wider, long-oval instead parallel side. The pronotum is more convex and the legs are stouter and shorter.

Distribution AND Biology. Saphanus piceus perovici $\mathrm{n}$. ssp. was collected by light traps in a very dry area of Pag Island, Croatia (Fig. 1). All the species of the genus Saphanus are normally collected in mountain forests, in cold and wet regions. It is very interesting to note that the vegetation of the surroundings where the new subspecies was collected are made by a vegetation made by overgrown karstic grasslands with Juniperus bushes. Accordingly, it is very likely that the larva feed on the roots of Juniperus sp., the only large plant found in the area.

Etymology. We dedicate this new subspecies to Mag. Franjo Perović, a former curator of the Natural HistoryMuseum in Zagreb (Croatia). He dedicated most of his life to study insects and to collect a rich entomological collection of diverse orders, inspiring many generation of entomologists.

REMARKS. Saphanus piceus perovici $\mathrm{n}$. ssp. is close to $S$. piceus ganglbaueri due to the stouter shape of the body, the shorter antennae and legs and the absence of evident carina on elytra. A new characteristic distinguish $S$. piceus piceus and $S$. piceus ganglbaueri and it is the ratio between the second and the third and the ratio between the fourth and fifth antennal segments. In the nominal form the third segment is more than three times longer than the second and in the subspecies $S$. piceus ganglbaueri it is little more than two times longer. The fourth segment is similar in length to the fifth in S. piceus piceus and evidently shorter in $S$. piceus ganglbaueri. The new subspecies shows the same combinations of $S$. piceus ganglbaueri but the third and the fourth segments are even shorter. Due to this, it is more similar to $S$. piceus bartolonii. It can be distinguished from all the other subspecies of $S$. piceus due to the very regular sculpture on the pronotum, made by regular points. These points are not so regular in all the other subspecies. The shining line on the middle of pronotum is completely missing (or only very thin 

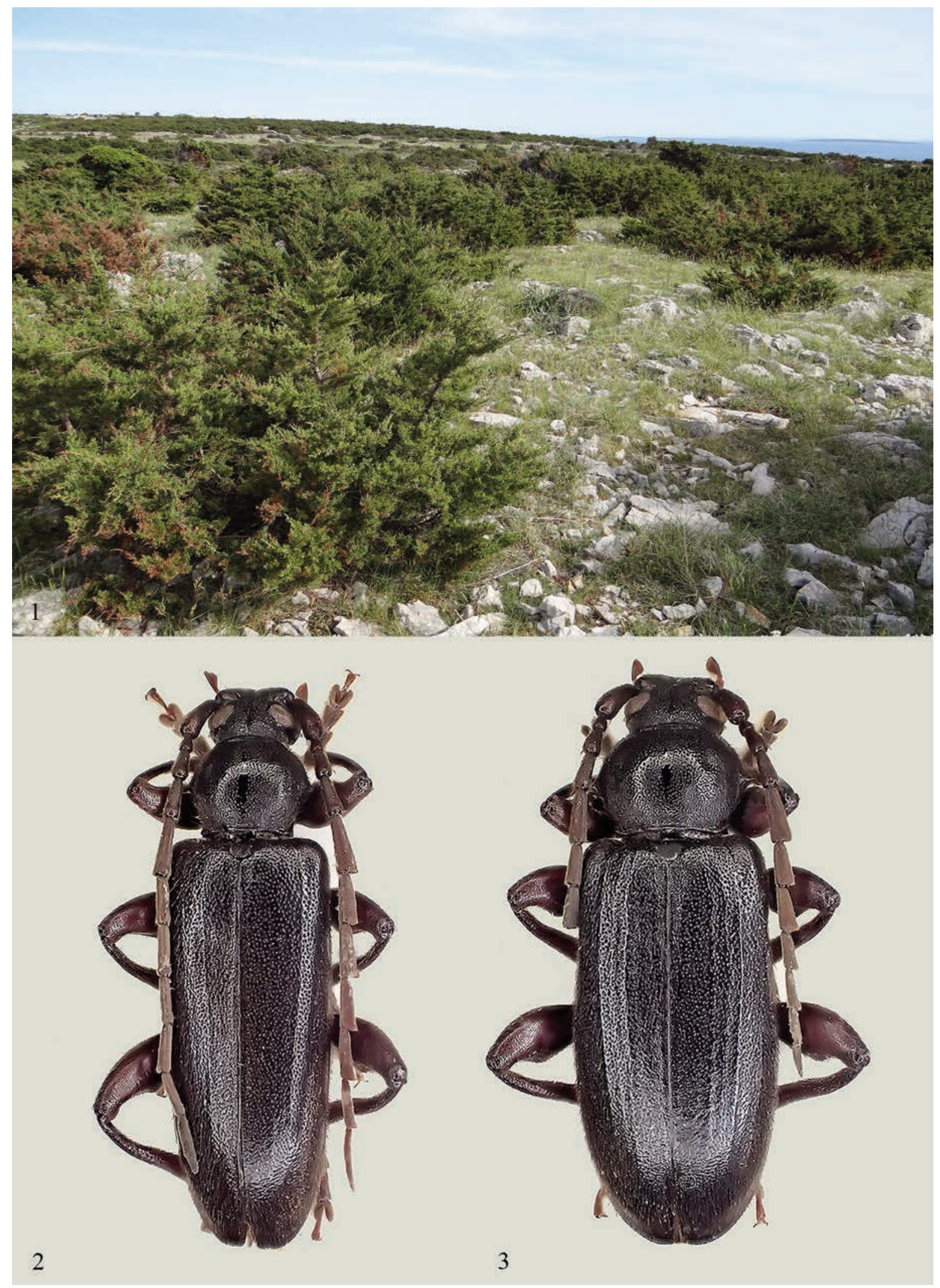

Figure 1. The habitat on Pag Island (Croatia) where Saphanus piceus perovici n. ssp. was collected.

Figure 2. Saphanus piceus perovici n. ssp., holotypus. Figure 3. Saphanus piceus perovici n. ssp., paratypus female. 
and short) in S. piceus ganglabueri. The vestiges of the elytral carinas are more evident than in $S$. piceus ganglabueri.

\section{REFERENCES}

Löbl I. \& Smetana A., 2010. Catalogue of Paleartic
Coleoptera. 6. Chrysomeloidea. Apollo Books, Stenstrup, $924 \mathrm{pp}$.

Sama G. \& Rapuzzi P., 1993. Revisione dei generi Saphanus Serville, 1834 e Drymochares Mulsant, 1847. Lambillionea, 93: 278-294.

Rapuzzi P. \& Sama G., 2014. Description of nine new species of Longhorn beetles. Munis Entomology \& Zoology, 9: 1: 1-16. 